\title{
EFECTO DEL GEL DE Aloe vera L. MODIFICADO EN EL TRATAMIENTO DE HEPATOTOXICIDAD Y ALOPECIA INDUCIDAS CON CCL $\mathrm{C}_{4}$ Y DMSO EN RATONES
}

\author{
Effect of modified Aloe vera L gel in the treatment of liver toxicity and induced alopecia with \\ $\mathrm{CCl}_{4}$ and DMSO in mice
}

Félix Saavedra ${ }^{1}$, Gloria Gordillo², Haydée Zúñiga² ${ }^{2}$ José A. Apesteguía ${ }^{3}$, Henry Ostos ${ }^{4}$

${ }^{1}$ Instituto de Investigación en Ciencias Farmacéuticas y Recursos Naturales "Juan de Dios Guevara”; ${ }^{2}$ Instituto de Química Biológica, Microbiología y Biotecnología "Marco Antonio Garrido Malo; ${ }^{3}$ Laboratorio de Toxicología y Química Legal.

${ }^{4}$ Bioterio. Facultad de Farmacia y Bioquímica. UNMSM.

\section{RESUMEN}

El propósito del presente estudio fue evaluar si la pérdida del pelaje y variación de enzimas hepáticas, aspartato aminotransferasa (AST) y alanina aminotransferasa (ALT), producidas en ratones albinos por administración vía oral de tetracloruro de carbono y dimetilsulfóxido (DMSO) (1:1), dosis $2 \mathrm{~mL} / \mathrm{Kg}$, son procesos reversibles cuando se administra gel de sábila modificado (GSM) por vía oral a dosis diaria de $8 \mathrm{~mL} / \mathrm{Kg}$ de peso. Según los análisis realizados a los 13 , 18 y 33 días de iniciado el tratamiento con GSM, se evidencia disminución progresiva y significativa de AST y ALT, sin variaciones en las proteínas y fosfatasas; en cambio, el nivel de triglicéridos experimenta disminución significativa durante la primera semana respecto a los roedores que recibieron la mezcla $\mathrm{CCl}_{4}+\mathrm{DMSO}$ (grupo A), ejemplares que además recuperaron el pelaje en el pecho y hocico a los 33 días de iniciado el experimento. Los ratones de los grupos control, GSM, DMSO+alimento y alimento+agua, no presentan variación significativa en los indicadores estudiados.

Palabras clave: Hepatotoxicidad, $\mathrm{CCl}_{4}$, DMSO, alopecia, Aloe vera.

\section{SUMMARY}

The purpose of this study was to assess whether the loss of fur and changes in liver enzymes, aspartate aminotransferase (AST) and alanine aminotransferase (ALT), produced in albino mice by oral administration of carbon tetrachloride and dimethyl sulfoxide (DMSO) (1:1), $2 \mathrm{~mL} / \mathrm{kg}$ dose, are reversible processes when administered modified aloe gel (GSM) orally daily dose of $8 \mathrm{~mL} / \mathrm{kg}$ of weight. Tests carried out at 13, 18 and 33 days from starting treatment with GSM, was evidenced significant and progressive decrease in AST and ALT without significant variations in proteins and phosphatases; whereas triglyceride level by the effect of GSM (group B), experienced significant decrease during the first week compared to mice given $\mathrm{CCl}_{4}+\mathrm{DMSO}$ mixture (group A), specimens that also recovered the fur on its chest and muzzle at 33 days of starting the experiment. The mice in the groups: control, GSM, DMSO+feed and water+feed, did not present significant variation in the studied indicators.

Keywords: Hepatotoxicity, $\mathrm{CCl}_{4}$, DMSO, alopecia, Aloe vera.

\section{INTRODUCCIÓN}

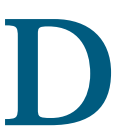
esde tiempos remotos, Aloe vera (sábila) se utiliza en todas las latitudes para el tratamiento de diversas enfermedades de órganosysistemas del ser humano, debidoa su contenido en vitaminas, enzimas, minerales, polisacáridos, antraquinonas, carbohidratos, hormonas, aminoácidos, flavonoides, esteroides, lignina y ácido salicílico, atribuyéndose a los polisacáridos actividades biológicas como: cicatrizante, antimicótica, hipoglicemiante, antiinflamatoria, anticáncerosa, immunomoduladora y gastroprotectoras $^{(1)}$.

El uso de tetracloruro de carbono $\left(\mathrm{CCl}_{4}\right)$ en animales de experimentación es un modelo adecuado para elucidar los mecanismos de acción de los efectos hepatotóxicos como: degeneración grasa, fibrosis, cirrosis, tumores y carcinomas hepáticos. El metabolismo del $\mathrm{CCl}_{4}$ es iniciado por enzimas citocromo $\mathrm{P}-450$, para formar el radical triclorometilo $\left(\cdot \mathrm{CCl}_{3}\right)$ que reacciona con oxígeno formando el radical triclorometilperoxil $\left(\cdot \mathrm{CCl}_{3} \mathrm{OO}\right)$; este compuesto genera fosgeno $\mathrm{y}$ reacciona con la molécula antioxidante glutatión o cisteína, especies altamente reactivas. La desmedida producción de estos y otros radicales libres, causan peroxidación lipídica de la membrana celular y activación de factores de transcripción que regulan los genes del TNF $\alpha$ (citoquina pro inflamatoria cuya sobreexpresión favorece la apoptosis y activación 
de las células estelares) y de otros involucrados en la regeneración tisular, lo cual se comprobó observando modificaciones morfológicas de las células hepáticas y formaciones tumorales ${ }^{(2,3)}{ }^{3}$. En este sentido, los polisacáridos y flavonoides de Aloe barbadensis Miller, y los polisacáridos y compuestos fenólicos del gel de Aloe arborescens Miller han demostrado potencial antioxidante in vitro ${ }^{(4,5)}$.

El $\mathrm{CCl}_{4}$ se administra a ratas Wistar y ratones albinos $\left(\mathrm{BALB} / \mathrm{c}\right.$ ) y cepa $\mathrm{C}_{57} \mathrm{BL} / 6$, en la mayoría de los casos combinado con aceite de oliva, aceite de maíz o parafina líquida, vía intraperitoneal u oral (dosis o, 4 a $2 \mathrm{~mL} / \mathrm{Kg}$.); también se aplica por vía subcutánea o por inhalación. Este modelo origina el incremento de las enzimas hepáticas alanina aminotransferasa (ALT), marcador específico de daño al hepatocito, aspartato aminotransferasa (AST), lactato deshidrogenasa (LDH), fosfatasa alcalina (ALP), proteínas totales (TP), triglicéridos (TG) y malondialdehído (MDA), mientras disminuye la actividad de las enzimas antioxidantes superóxido dismutasa (SOD), catalasa (CAT), glutatión reductasa $(\mathrm{GR})$ y glutatión peroxidasa $(\mathrm{GPX})^{(6)}$.

Aloe vera L. tiene acción moduladora en los perfiles de las enzimas asociadas con el metabolismo carcinógeno en diversos órganos de ratones. En el hígado, se presenta incremento significativo en los niveles de ácido sulfhídrico soluble (-SH), NADPHcitocromo $\mathrm{P}_{450}$ reductasa, NADH-citocromo b5 reductasa, glutatión S-transferasa (GST), DT-diaforasa (DTD), SOD, CAT, GPX y GR. De esta manera, Aloe vera es un claro inductor del sistema enzimático fase II ${ }^{(7)}$.

La microscopía electrónica evidenció que la pulpa está constituida por células claras y grandes, en cuyas paredes y membranas hay número limitado de organelas degeneradas distribuidas a lo largo.

Por centrifugación secuencial se obtienen tres componentes: hojas claras delgadas, micropartículas y líquido viscoso, que concuerdan con la pared celular, organelas celulares degeneradas y líquido viscoso del gel; estos tres componentes, representan 16,2 - 83,1\% del extracto seco del gel que se localiza en la parte central de la hoja. La composición de hidratos de carbono de cada componente fue distinta: el gel contenía mannano; las micropartículas, galactosa rica en polisacáridos; y las paredes celulares, un nivel inusualmente elevado de ácido galacturónico $(34 \% \mathrm{w} / \mathrm{w})$. Por tanto, los diferentes componentes estructurales de la pulpa se asocian con diferentes polisacáridos, en consecuencia, tienen diferente funcionalidad ${ }^{(8)}$.

Por hidrólisis ácida de los polisacáridos de Aloe vera $\mathrm{L}$., se obtuvo mayor cantidad de manosa, glucosa, galactosa y trazas de arabinosa, xilosa y ramnosa. En Aloe arborescens Miller, se detectó mayor cantidad de glucosa, también galactosa, arabinosa y trazas de xilosa ${ }^{(9)}$.

Para neutralizar la injuria hepática en roedores por $\mathrm{CCl}_{4}$, in vitro y in vivo, se han utilizado diversos componentes y extractos de diferentes aloes, por ejemplo, polvo de Aloe vera disuelto en acetato de etilo ${ }^{(10)}$, extracto acuoso de las partes aéreas de Aloe barbadensis Mill ${ }^{(11)}$.

El extracto de Aloe vera L. Burm. F., administrado a conejos-dosisparaadulto $500 \mathrm{mg} / 70$ Kgdepeso, ajustada al peso del animal-, disminuye los niveles de ALT, AST y bilirrubina directa, lo que sugiere que la planta protege del estrés oxidativo e inhibe la acumulación de radicales libres mediante los fitoconstituyentes biológicamente activos como flavonoides y alcaloides ${ }^{(12)}$.

Los glicósidos totales de Aloe vera var. Chinensis, administrados porvía i.p. en ratasy ratones, disminuyen los niveles de GPT elevados por $\mathrm{CCl}_{4}$, tioacetamida y $\mathrm{D}$-amino-lactosa; también son útiles en $86 \%$ pacientes con hepatitis crónica ${ }^{(13)}$.

Filatov, investigando sustancias bioestimulantes para el tratamiento de cataratas, guardó hojas enteras de Aloe vera L. a $4^{\circ} \mathrm{C}$ durante dos semanas y en éstas se sintetizaron sustancias que incrementan la adaptación de las hojas a las condiciones adversas y retardan su muerte ${ }^{(14)}$. Con este antecedente, en lugar de refrigerar las hojas, se refrigeró durante tres semanas el gel licuado sin aloína, y este gel de sábila modificado (GSM) produjo mayor motilidad en el íleo de rata aislado respecto al gel fresco ${ }^{(15)}$.

El objetivo del presente estudio es comprobar si el GSM presenta efecto hepatoprotector y revierte la alopecia inducida en ratones albinos hembra intoxicadas con $\mathrm{CCl}_{4}$ mezclado en DMSO.

\section{MATERIALES Y MÉTODOS}

\section{Reactivos químicos}

Todos los reactivos utilizados fueron grado analítico.

\section{Preparación del gel de sábila modificado (GSM)}

450 g de trozos de hojas de Aloe vera Linneo, se maceraron en $600 \mathrm{~mL}$ de agua destilada, después de dos horas se renovó el agua y se maceró por una hora más. Enseguida, sobre una superficie adecuada, se cortaron los bordes espinosos y se separó la parte plana, de manera que la parte convexa conserve la mayor cantidad de gel, el cual, luego es separado con 
espátula y llevado al vaso de una licuadora. El gel espeso y espumoso obtenido, se vierte en pequeños recipientes de vidrio de 100 a $120 \mathrm{~mL}$ con tapa, sin llenarlos -para evitar se rompan por la dilatación del gel-y se congelan a $\mathrm{O}^{\circ} \mathrm{C}$ durante dos semanas. Iniciado el experimento, cada dos días se descongela un frasco y se separa, en recipiente pequeño con tapa, la cantidad aproximada a utilizar guardando el recipiente original en la parte inferior de la refrigeradora. Se repitió esta secuencia hasta concluir el experimento.

Durante la maceración de los trozos de Aloe vera en agua, se disuelven los carbohidratos solubles -principalmente glucosa-, ácidos orgánicos y aloína (16). Este último compuesto es el acíbar amarillento que fluye de los túbulos pericíclicos de la hoja de la planta, cuyo principal componente es la aloe emodina, la cual, administrada a la concentración de $50 \mathrm{mg} / \mathrm{Kg}$, demostró tener algún efecto hepatoprotector, así como en la respuesta inflamatoria posterior a la peroxidación lipídica en ratas intoxicadas con $\mathrm{CCl}_{4}{ }^{(17)}$. Sin embargo, cuando se administra, a ratas albinas, el extracto liofilizado de las hojas de Aloe barbadensis (que incluye todos los nutrientes biológicamente activos, además aloína $\mathrm{A}$, aloe emodina y otros derivados antraquinónicos) en agua de bebida al 2-3\%, durante 104 semanas - sin período de descanso-, se desarrollan neoplasias en diferentes órganos y sistemas ${ }^{(18)}$.

\section{Animales de experimentación}

Se utilizaron ratones albinos hembra, cepa NIH, de 20-25 g, del Instituto Nacional de Salud, aclimatados por siete días, con libre acceso a alimento y agua, bajo condiciones establecidas detemperatura $\left(23^{\circ} \mathrm{C}\right)$ y humedad (60-70\%), se les agrupó en cuatro grupos de cinco cada uno, suminstrándoles tratamiento oral por 32 días.

Grupo A: Recibieron, por vía oral, II gotas de la mezcla $\mathrm{CCl}_{4}+$ DMSO (1:1) equivalente a $\mathrm{CCl}_{4}, 2 \mathrm{~mL} / \mathrm{Kg}$ de peso durante tres días; luego, por 29 días, IV gotas de GSM equivalente a $8 \mathrm{~mL} / \mathrm{Kg}$ de peso.

Grupo B: GSM $8 \mathrm{~mL} / \mathrm{Kg}$ durante 32 días.

Grupo C: DMSO $2 \mathrm{~mL} / \mathrm{Kg}$ de peso por 32 días.

Grupo D: Control, acceso librea alimentoy agua por 32 días.

\section{Preparación de las muestras biológicas}

Seanestesiaron los ratones y por punción cardiaca se les extrajo sangre, la cual se dejó en reposo para retracción del coágulo y se centrifugó para obtener el suero para las determinaciones de alanina aminotransferasa (ALT), aspartato aminotransferasa (AST), fosfatasa alcalina (ALP), proteínas totales y triglicéridos.

\section{RESULTADOS}

\section{Observación ma'croscópica}

Grupo A. Al inicio del experimento, por acción del $\mathrm{CCl}_{4}$, presentaron pérdida de pelo a nivel del hocico, cuello y parte del pecho. Conforme transcurren las semanas, por efecto del GSM, es notorio el crecimiento de pelo en dichas zonasy, conformeseiban sacrificandolos roedores, mejora el aspecto -color y tamaño- de las vísceras (pulmones, hígado, intestino, bazo), en especial el hígado, el cual inicialmente estuvo fragmentado en lóbulos de color rojo oscuro, mientras que en los últimos sacrificios, luce íntegro y de color rojo vinoso. Asimismo, los ejemplares sacrificados antes de las dos semanas, a nivel medio de la línea interlobular del hígado, presentaron una pequeña vesícula oleosa amarillenta la cual desaparece al finalizar la tercera semana de tratamiento.

Grupo B. Algunos ejemplares presentaron acumulación de grasa debajo de la piel. El grupo se caracterizó por el rápido metabolismo de alimentos y líquidos, presentando el intestino casi vacío, excesiva diuresis, incremento de peso y vísceras con aspecto de estar siempre bien irrigadas.

Grupos C y D. Internamente las vísceras lucían normales y mantuvieron el incremento de peso con la edad.

\section{DISCUSIÓN}

La administración de $\mathrm{CCl}_{4}$, en ratones, origina necrosis centrilobular con degeneración de hepatocitos y una sobreproducción del factor de crecimiento del hepatocito (HGF), el cual lo protege del tóxico; sin embargo, la isoforma transgénica $\mathrm{NK}_{2}$ neutraliza in vitro el HGF endógeno en términos de promover la injuria hepática generada por el xenobiótico. Esto se comprueba administrando $\mathrm{CCl}_{4}$ a ratones transgénicos HGF y NK2, y al grupo control WT, observándose incremento de ALT dos a tres veces en el grupo NK2, respecto al grupo WT, y disminución dramática de dicha enzima en el grupo HGF, respecto al grupo WT ${ }^{(19)}$, lo que sugiere que cuando se administra GSM y disminuye el nivel de ALT, las expresiones RNA del grupo de ratones intoxicados con la mezcla $\mathrm{CCl}_{4}+\mathrm{DMSO}$ se desplazan hacia expresiones RNA análogas que favorecen la sobreproducción de HGF.

Después de haber recibido la tercera dosis de la mezcla $\mathrm{CCl}_{4}+\mathrm{DMSO}$, los roedores del grupo A presentaron aspecto y pelaje muy deteriorado. Transcurridos cinco días del experimento, los ratones del grupo A -que habían recibido GSM por dos días-, 
Tabla 1. Variaciones de algunos indicadores bioquímicos en ratones hembra por efecto de CCl4 disuelto en DMSO (1:1) y su tratamiento con ingesta de GSM comparados con grupo control.

\begin{tabular}{|c|c|c|c|c|c|c|c|c|}
\hline Grupo & $\begin{array}{c}\text { Sustancia } \\
\text { adm. vía oral } \\
\text { (mL/Kg) }\end{array}$ & $\begin{array}{c}\text { Tratamiento } \\
\text { Días }\end{array}$ & $\begin{array}{c}\text { Peso } \\
\text { (*promedio) } \\
\text { (g) }\end{array}$ & $\begin{array}{l}\text { AST } \\
\text { UI/L }\end{array}$ & $\begin{array}{l}\text { ALT } \\
\text { UI/L }\end{array}$ & $\begin{array}{c}\text { Proteínas } \\
\text { g/dL }\end{array}$ & Fosfatasas & $\begin{array}{c}\text { Triglicéridos } \\
\text { (mg/dL) }\end{array}$ \\
\hline \multirow{3}{*}{ A } & \multirow{3}{*}{$\begin{array}{c}\mathrm{CCl}_{4}+\mathrm{DMSO} \\
(1: 1) \\
2 \mathrm{~mL} / \mathrm{Kg}\end{array}$} & 5 & 24,0 & 208 & 235 & 7,2 & 310 & 148 \\
\hline & & 13 & $* 26,6$ & 193,5 & 207 & 6,95 & 283 & 88 \\
\hline & & 32 & *35,25 & 93 & 122 & 8,25 & 223 & 73,5 \\
\hline \multirow{3}{*}{ B } & \multirow{3}{*}{$\begin{array}{c}\mathrm{GSM} \\
8 \mathrm{ml} / \mathrm{Kg}\end{array}$} & 13 & 31,1 & 55 & 73 & 7,6 & 225 & 67 \\
\hline & & 18 & *33,0 & 60,5 & 54 & 7,3 & 166 & 45 \\
\hline & & 32 & $* 34,0$ & 46,5 & 47 & 7,5 & 162 & 106 \\
\hline \multirow{4}{*}{ C } & \multirow{4}{*}{$\begin{array}{c}\text { DMSO } \\
2 \mathrm{ml} / \mathrm{Kg}\end{array}$} & 5 & 27,2 & 67 & 78 & 6,5 & 216 & 198 \\
\hline & & 18 & 31,6 & 56 & 66 & 6,8 & 196 & 132 \\
\hline & & 28 & $* 33,0$ & 45 & 49 & 7,0 & 155 & 104 \\
\hline & & 32 & 35,0 & 48 & 53 & 7,3 & 155 & 79 \\
\hline \multirow{3}{*}{ D } & \multirow{3}{*}{ CONTROL } & 5 & 35,4 & 50 & 69 & 6,9 & 235 & 85 \\
\hline & & 18 & $* 35,5$ & 48 & 52 & 7,3 & 155 & 142 \\
\hline & & 32 & $* 39,0$ & 67 & 98 & 7,8 & 186 & 55 \\
\hline
\end{tabular}

según la tabla 1, presentan incremento de AST en 2,5 veces y ALT en más de 2 veces, respecto al promedio de dichos indicadores en los tres grupos control B, C y D; en cambio, los niveles de triglicéridos se incrementan en el grupo A y en el grupo con DMSO (grupo C), respecto al grupo control D. Los indicadores proteínas y fosfatasas no presentan variaciones significativas en los tres grupos control, pero de manera relativa, están ligeramente elevados en el grupo A.

Durante el transcurso del tratamiento para el grupo A (3 días con la mezcla $\mathrm{CCl}_{4}+\mathrm{DMSO}$ y 10 días con GSM), la cinética en la disminución de los niveles de AST y ALT es pequeña, pero la recuperación de movilidad y pelo en los roedores es ostensible, tal como se muestra en la figura 2.

Al finalizar el experimento, el grupo A por efecto del GSM -durante 29 días- disminuye los niveles de AST y ALT en casi el doble que el promedio de los equivalentes de los tres grupos control, lo cual sugiere secuelas hepáticas de lenta remisión. Sin embargo, respecto a los niveles iniciales -3 días de tratamiento con GSM- los niveles de dichas enzimas se han reducido en $50 \%$. Por otro lado, conforme transcurre el experimento los ratones del grupo A tratados con GSM, presentan incremento del nivel de proteínas y disminución de fosfatasas, además de mejoría de la función hepática, por lo que se propone que el GSM intervieneen algunas rutas metabólicasque promueven el desarrollo del folículo piloso y crecimiento de pelo en los roedores de este grupo. Al parecer, el GSM restablece la producción de células productoras del factor de crecimiento epitelial, teniendo en cuenta un estudio con ratones mutantes carentes de células productoras de dicho factor ${ }^{(20)}$.

Se evidencia la participación de los componentes químicos presentes en GSM, observando crecimiento de pelo alrededor del cuello y pecho en ratones hembra (fig. 1, 2,3) a los cuales se indujo alopecia coon la mezcla $\mathrm{CCl}_{4}+$ DMSO.

El pelo es un ejemplo notable de diferenciación celular especializada y el ratón es un excelente modelo para investigar la biología del crecimiento y estructura del pelo. Se ha demostrado en ratones transgénicos disminución sustancial en la proteína alta en azufre y la proteína alta en los grupos del glicina/tirosina, constituyentes de la matriz de queratina delç pelo ${ }^{(21)}$.

Entre los componentes del gel de sábila se hallan los aminoácidos esenciales metionina, histidina, arginina, triptófano, lisina, valina, leucina e isoleucina. El aminoácido sulfurado metionina es el componente indispensable para la síntesis de queratina, proteína principal del filamento piloso. A este aminoácido, que ingresa al organismo con los alimentos, se le considera "aminoácido de partida" en la síntesis de proteínas a nivel de los ribosomas. Asimismo, L-metionina es donante fundamental de azufre, aporta el grupo SH indispensable para la producción de queratina, glutatión, carnitina, fosfolípidos y otras sustancias importantes. La metionina es la fuente de azufre en la biosíntesis de cisteína (precursor del glutatión), la cual también participa en la elaboración de queratina ${ }^{(22)}$.

La L-Arginina es substrato para las enzimas denominadas NO-sintasas, cuyo trabajo conduce a la formación de óxido de nitrógeno (NO), el cual es un poderoso vasodilatador que regula el ingreso de sangre y nutrientes en órganos y tejidos del organismo, entre ellos, los folículos pilosos. La arginina es indispensable para la síntesis de hormonas (como la del crecimiento) y procesos del intercambio nitrogenado ${ }^{(23)}$. El factor de crecimiento semejante a la insulina tipo 1 (IGF-1) es sintetizado principalmente en el hígado (pero también en la glándula mamaria y otros tejidos) y desempeña diversos roles importantes en la proliferación, 


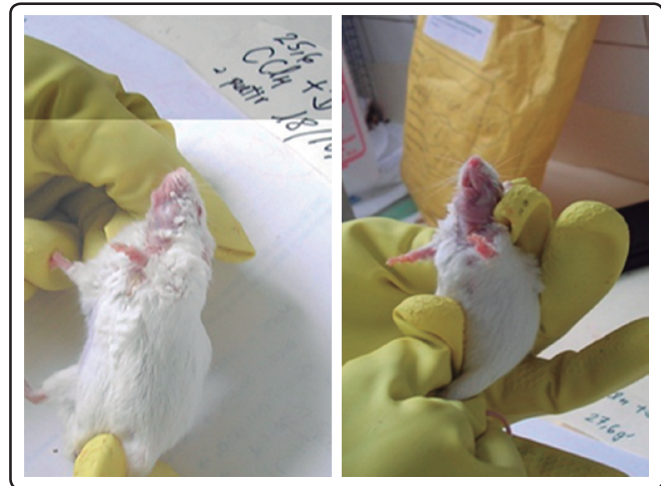

Figura 1. Vista de dos ejemplares del grupo A tratados con GSM durante tres días (pesos 25,6 y 27,6 g), antes de ser sacrificados.

diferenciación y funciones de la célula, por consiguiente contribuye al mantenimiento e integridad de los tejidos. Se sabe que la hormona de crecimiento $(\mathrm{GH})$ aumenta los niveles de IGF-1 en suero estimulando la producción hepática, pero no se conoce con certeza el mecanismo por el cual la producción local de IGF-1 en tejidos individuales está regulada. La estimulación de neuronas sensoriales por capsaicina (componente irritante de ajíes y pimientos) incrementa los niveles de IGF-1 y del IGF1-RNA en diversos órganos vía incremento de calcitonina péptido relacionada con el gen (CGRP) en ratones. El fitoestrógeno isoflavona aumenta la producción de CGRP aumentando su transcripción en neuronas sensoriales. La administración de capsaicina e isoflavona aumenta producción de IGF-I en folículos pilosos, por consiguiente favorece el crecimiento de pelo en ratones y en voluntarios con alopecia ${ }^{(24)}$. Es decir, el GSM, al normalizar la función hepática, favorece la producción de IGF-1 regenerando el pelo en los roedores tratados con la mezcla $\mathrm{CCl}_{4}+\mathrm{DMSO}$.

El gel también contiene vitaminas y minerales que favorecen el crecimiento del pelo, por ejemplo, la vitamina C (ácido ascórbico), un poderoso antioxidante que desempaña un rol importante en la regulación de los proVcesos óxido-reductores, participa en la síntesis de colágeno -y procolágeno-, metabolismo del ácido fólico y hierro, síntesis de hormonas esteroides y catecolaminas. En presencia de cantidad adecuada de ácido ascórbico, se incrementa significativamente la estabilidad de las vitaminas $\mathrm{B} 1, \mathrm{~B} 2, \mathrm{~A}, \mathrm{E}$, ácidos pantoténico y fólico, también necesarios para el normal funcionamiento del folículo piloso y crecimiento del pelo ${ }^{(25)}$.

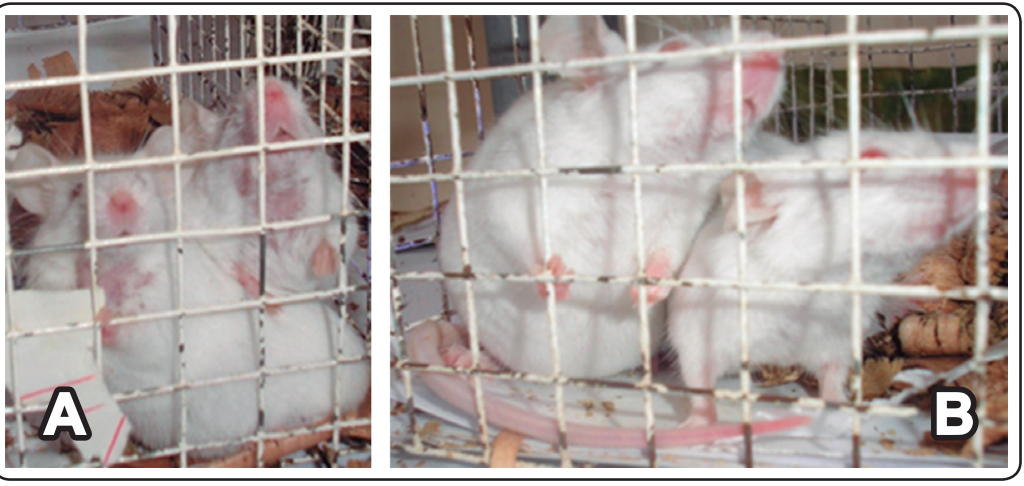

Figura 2. Recuperación del pelo en ratones hembra por efecto de GSM, previamente

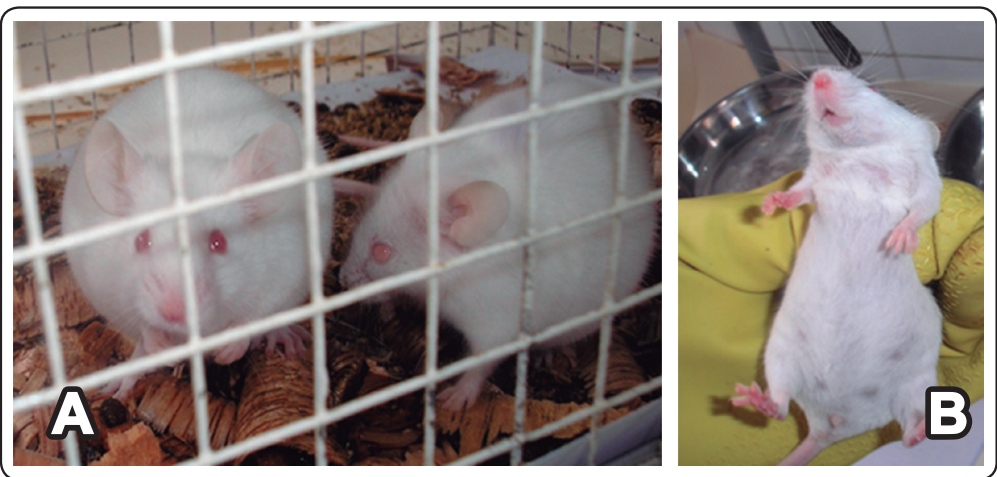

Figura 3. Los mismos roedores mostrando recuperación anímica y de pelaje por tratamiento con GSM durante 29 días (pesos 37,0 y 33,5 g.) A) Vista de ambos jemplares. B) Vista del pecho y vientre de uno de ellos.

Entre los ingredientes minerales, el gel contiene zinc, selenio, magnesio y cobre (también calcio, potasio y cromo) que forman parte del centro activo de enzimas antioxidantes. El $\mathrm{Cu}$ forma parte del centro activo de muchas enzimas y también participa en los procesos de crecimiento y desarrollo de la célula y tejidos. Junto con el ácido ascórbico el $\mathrm{Cu}$ apoya el estado activo del sistema inmunológico y sostiene la estructura de la enzima SOD; además la elasticidad de la piel se mantiene con ayuda de colágeno en cuya composición participa el cobre. El Zn es importante para el ciclo vital del pelo, desempeña efecto antiandrógeno, estimulando el crecimiento del pelo.

Por los resultados obtenidos es evidente que el GSM contiene la mayoría de los componentes químicos de Aloe vera L., entre ellos, polisacáridos, aminoácidos esenciales, enzimas antioxidantes y minerales complexados a moléculas orgánicas.

\section{CONCLUSIONES}

El gel de sábila modificado (GSM) tiene efecto hepatoprotector en ratones hembra intoxicados con $\mathrm{CCl}_{4}$ disuelto en DMSO, a juzgar por la disminución de los niveles de las transaminasas (ALT y AST). 
El GSM presenta efecto hipolipemiante, ya que disminuye los triglicéridos.

La alopecia generada por la mezcla $\mathrm{CCl}_{4}+\mathrm{DMSO}$ es reversible con un mes de tratamiento con GSM.

\section{REFERENCIAS BIBLIOGRÁFICAS}

1. Hamman JH. Composition and Applications of Aloe vera Leaf Gel. Molecules 2008, 13(8): 1599-616.

2. Manibusan MK, Odin M, Eastmond DA. Postulated carbon tetrachloride mode of action: a review. J Environ Sci Health C Environ Carcinog Ecotoxicol Rev 2007; 25(3): 185-209.

3. Moreno M. Investigación de nuevas estrategias Terapéuticas para la inflamación y cirrosis hepática. [Tesis para optar el grado de Doctor en Medicina]. Universidad de Barcelona. 2010. Pág. 29-30. [En línea] Acceso o8 de febrero 2013. Disponible en: www.tdx.cat/ bitstream/10803/2326/1/MMS_TESIS.pdf

4. Hu Y, Xu J, Hu Q. Evaluation of antioxidant potential of Aloe vera (Aloe barbadensis Miller) extracts. J Agric Food Chem 2003; 51(26): 7788-91.

5. Olennikov DH, Zilfikarov YH, Ybraguimov TA, Toropova AA and Tanxayeva LM. Composición química del extracto de Aloe arborescens Miller y su actividad antioxidante in vitro. Ximia pastítelnova siriá 2010; 3: 83-90. [En línea] Acceso 02 de enero 2014. Disponible en: www.chem.asu. $\mathrm{ru} /$ chemwood/volume14/2010_03/1003_083.pdf

6. Young J K, Dong W K and Chae Ch Ch. Carbon tetrachloride $\left(\mathrm{CCl}_{4}\right)$-induced mouse liver damage and antioxidant activities of aqueous extracts of white, red, and fermented red ginseng. Journal of Trace Analysis in Food and Drugs 2013; 1: 22-9.

7. Singh RP, Dhanalakshmi S, Rao AR. Chemomodulatory action of Aloe vera on the profiles of enzymes associated with carcinogen metabolism and antioxidant status regulation in mice. Phytomedicine 2000; 7(3): 209-19.

8. Ni Y, Turner D, Yates KM, Tizard I. Isolation and characterization of structural components of Aloe vera L. leaf pulp. Int Immunopharmacol 2004; 4(14):1745-55.

9. Larionova M, Menéndez R, Valiente O, Fusté V. Estudio químico de los polisacáridos presentes en Aloe vera $\mathrm{L}$. y Aloe arborescens Miller cultivados en Cuba. Rev Cubana Plant Med 2004; 9(1) [En línea] Acceso 23 febrero 2013. Disponible en http://scielo.sld.cu/scielo.php?script=sci_ arttext\&pid=S1028-47962004000100004\&lng=en .

10. Norikura T, Kennedy DO, Nyarko AK, Kojima A, Matsui-Yuasa I. Protective effect of aloe extract against the cytotoxicity of 1,4-naphthoquinone in isolated rat hepatocytes involves modulations in cellular thiol levels. Pharmacol Toxicol 2002; 90(5): 278-84.

11. Chandan BK, Saxena AK, Shukla S, Sharma N, Gupta DK, et al. Hepatoprotective potential of Aloe barbadensis Mill. against carbon tetrachloride induced hepatotoxicity. J Ethnopharmacol 2007; 111(3): 560-6.
12. Sultana N, Najam R. Gross toxicities and hepatoprotective effect of Aloe vera (L) Burm F. International Research Journal of Pharmacy 2012: 3(10): 106-110.

13. Fan YJ, Li M, Yang WL, Qin L, Zou J. Protective effect of extracts from Aloe vera L. var. chinensis (Haw.) Berg. on experimental hepatic lesions and a primary clinical study on the injection of in patients with hepatitis. Zhongguo Zhong Yao Za Zhi 1989; 14(12): 746-8.

14. Mashkovsky M.D. Lekartsvenni Sriedsva (Sustancias medicinales) T1. Edit Medicina. Moscú, 1986. p. 188.

15. Saavedra F, Carreño M, Rojas L, Almonacid A, Ávila $\mathrm{J}$, et al. Variación fisicoquímica del aloe y su efecto farmacológico. XII Jornadas de Investigación en Ciencias Farmacéuticas y Bioquímicas 2009: 30.

16. Páez A, Gebre M, González ME, Tschaplinski TJ. Growth, soluble carbohydrates, and aloin concentration of Aloe vera plants exposed to three irradiance levels. Environ Exp Bot 2000; 44(2): 133-9.

17. Arosio B, Gagliano N, Fusaro LM, Parmeggiani L, Tagliabue $\mathrm{J}$, et al. Aloe-Emodin Quinone Pretreatment Reduces Acute Liver Injury Induced by Carbon Tetrachloride. Pharmacology \& Toxicology 2000; 87(5), 229-33.

18. U.S. Department of Health and Human Services. National Toxicology Program. NTP Technical report on the toxicology and carcinogenesis studies of a nondecolorized whole leaft extract of Aloe barbadensis Miller (Aloe vera) in F344/N rats and $\mathrm{B}_{6} \mathrm{C}_{3} \mathrm{~F}$, mice (drinking water study). Scheduled Peer Review Date: April 5, 2011 NTP TR 577: 223 [En línea] Acceso o5 noviembre 2012. Disponible en: ntp.niehs.nih.gov/Ntp/ About_Ntp/Trpanel/2011/.../DraftTR577.Pdf .

19. Otsuka T, Takagi H, Horiguchi N, Toyoda M, Sato K, et al. $\mathrm{CCl}_{4}$-induced acute liver injury in mice is inhibited by hepatocyte growth factor overexpression but stimulated by NK2 overexpression FEBS Letters 2002; 532(3): 391-5.

20. Benavides F, Guénet JL. "Manual de Genética de Roedores de Laboratorio" Capítulo IX. Los roedores de laboratorio como modelo de enfermedades humanas. Universidad Alcalá de Henares. [En línea] Acceso o5 de febrero 2013. Disponible en: www.transtechsociety.org/.../o9GENETICA.pdf

21. Fernandes MM, Lima CF, Loureiro A, et al. Keratinbased peptide: biological evaluation and strengthening properties on relaxed hair. International Journal of Cosmetic Science 2012; 34(4): 338-46.

22. Powell BC, Rogers GE. Cyclic hair-loss and regrowth in transgenic mice over expressing an intermediate filament gene. The EMBO Journal 1990; 9(5): 1485-93.

23. Lin MJ, Su MC, Tan CT, Su CC, Li SY, Lin RH. The effect of L-arginine on slow motility of mammalian outer hair cell. Hear Res 2003; 178(1-2): 52-8.

24. Harada N, Okajima K, Arai M, Kurihara H, Naomi Nakagata N. Administration of capsaicin and isoflavone promotes hair growth by increasing insulin-like growth factor-I production in mice and in humans with alopecia. Growth Hormone \& IGF Research 2007; 17(5): 408-15. 
25. Shada M. AL-Sudani, Maha K. AL-Mallak. Study on effect of Vitamin C and E (normal and double dose) on skin wounds healing in experimental rats wistar albino. Biology department, Science collage. University of Basrah. [En línea] Acceso 30 de diciembre 2013. Disponible en: http://www.iasj.net/iasj?func=fulltext\&aId=50304

\section{Correspondencia}

Nombre: $\quad$ Félix Enrique Saavedra Nizama

Dirección: Jr. Puno 1002 -Lima 1 - Perú

E-mail: fesn2709@gmail.com 